\title{
THE OXYGEN TIGHTROPE *
}

\author{
H. BarRme FAIRLEY, M.B., B.S., F.F.A.R.C.S. $†$
}

A PERUSAL of the literature confirms that anaesthetists are responsive to the whims of fashion. Thus, in recent years, one has witnessed the rise and fall in frequency of articles on techniques using the lytic cocktail, controlled hypotension, and hypothermia. In the field of respiration, with particular respect to anaesthesia, a cycle of interest has been noticeable-probably dictated in part by the development of improved measurement devices. A period of considerable interest in $\mathrm{pH}$ and changes in carbon dioxide tension-stimulated, no doubt, by the advent of the Severinghaus electrode and the development of the interpolation techniques-has been replaced more recently by a wave of studies of oxygenation. These have pivoted around arterial oxygen tension levels and have been made possible by the ready availability and efficiency of the oxygen electrode.

In Toronto, we too are followers of fashion and have become interested in certain aspects of oxygenation. Our findings in some respects confirm the work of others, while other data suggests trends not previously described.

I shall review some of the currently available information on oxygen transport from inspired air to cell, and particularly that information which indicates defects almost inseparable from anaesthesia and, possibly, from the management of respiratory failure by intermittent positive pressure ventilation. Secondly, I should like to suggest that the correction of these defects in oxygenation may not be as simple as one might initially believe. In fact, one may be sailing between the Scylla of hypoxia and the Charybdis of the complications of its prophylaxis.

The body oxygen store is largely confined to that present in combination with haemoglobin. When arterial oxygen desaturation occurs, hypoxia will supervene quickly and will be evident first in organs with the highest oxygen requirement, i.e., heart and cerebrum. Minor protection against falls in arterial oxygen tension is provided by the shape of the oxygen dissociation curve. However, below approximately $50 \mathrm{~mm}$. $\mathrm{Hg} P_{\mathrm{aO}_{2}}$, desaturation will be relatively rapid. The quantitative aspects of this topic, relative to anaesthesia, have been admirably reviewed by Bendixen and co-authors. ${ }^{1}$ On this occasion I should like to confine my remarks to certain changes in arterial oxygen tension seen in anaesthesia and during intermittent positive pressure ventilation. Before doing so, it is important to recognize that the changes discussed involve only a few of the many components in the oxygen transport chain (Fig. 1).

Arterial oxygen tension is dependent upon the factors determining the level of the alveolar tension (Fig. 2) and the efficiency with which the mixed venous blood equilibrates with the latter. Total equilibration is never achieved, and consequently the oxygen tension is always lower in the arterial blood than in the

- Based upon a guest lecture given at the Annual Meeting of the Australian Society of Anaesthetists, Adelaide, September, 1965. The investigations reported have been supported by grant \# MBA 1213 from the Medical Research Council of Canada.

†Department of Anaesthesia, University of Toronto. 
I. $\mathrm{P}_{1} \mathrm{O}_{2}$

2. VENTILATION

3. $\dot{V}_{A} / \dot{Q}_{C}$

4. $\mathrm{DO}_{2}$

5. CARDIAC OUTPUT

6. HAEMOGLOBIN Q DISSOCIATION

7. TISSUE PERFUSION

8. CELLULAR UTILIZATION

Figure 1. Oxygen transport chain.

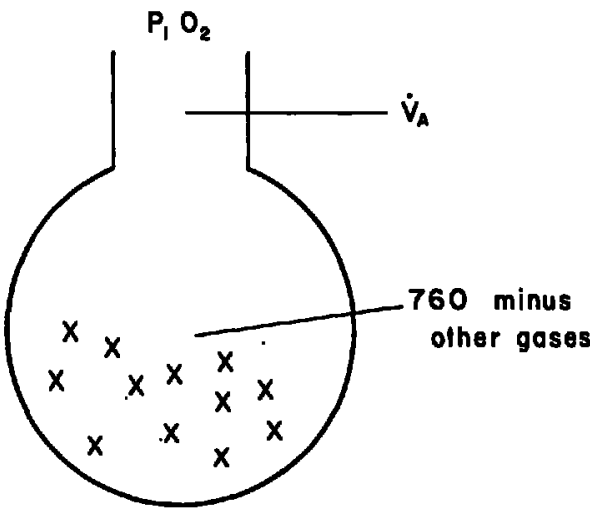

Figure 2. Factors determining alveolar oxygen tension. Crosses indicate molecules of gases other than oxygen, including water vapour, carbon dioxide, nitrogen, and agents eliminated during the unsteady state, e.g., following nitrous-oxide anaesthesia.

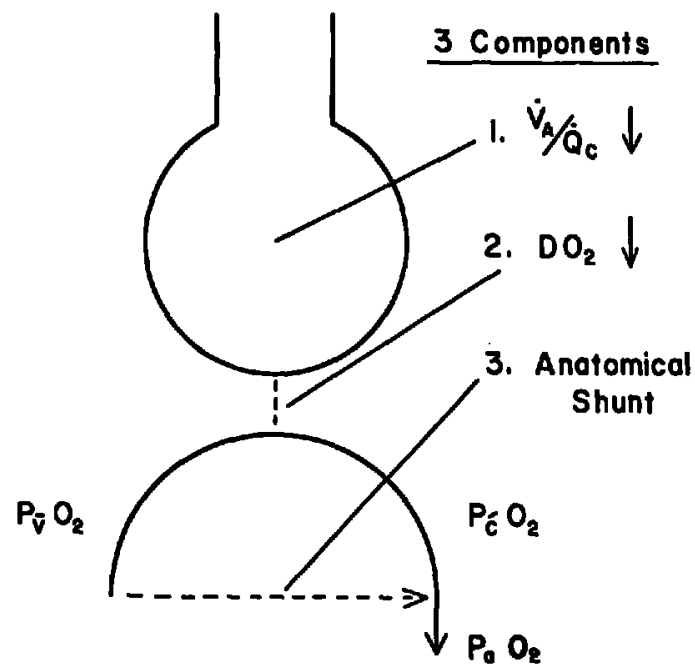

Figure 3. Factors which may contribute to the alveolar-arterial oxygen-tension difference.

alveoli. The possible causes of this alveolar-arterial oxygen difference are indicated in Figure 3. The extent of this tension gradient varies with age, ${ }^{2}$ and values up to 15 or $18 \mathrm{~mm}$. Hg are probably normal, although this figure should be lower in those under 30 . The gradient may be considered mathematically as though it is all created by a right-to-left shunt and, in young adults, the figures are equivalent to a two or three per cent shunt or calculated venous admixture. It is customary to refer to this as a physiological shunt. Farhi and Rahn ${ }^{3}$ have described the relative contribution of the components of the alveolar-arterial oxygen gradient, assuming a two per cent shunt, and have shown that the total gradient 
is dependent upon the alveolar oxygen tension. Thus, at an alveolar tension of $100 \mathrm{~mm}$. Hg the gradient may be 9 or $10 \mathrm{~mm}$. Hg. Assuming the same per cent physiological shunt, the gradient will be over $50 \mathrm{~mm}$. $\mathrm{Hg}$ when the alveolar tension rises to $200 \mathrm{~mm}$. Hg. In normal persons this gradient is caused by a combination of venous admixture resulting from anatomical shunt and inequality in ventilation-perfusion ratio. The relative contributions of these two components during anaesthesia have been only partially evaluated, ${ }^{4,5}$ However, an increased physiological shunt is a frequent occurrence, ${ }^{0-12}$ and it is the magnitude of this shunt which will determine arterial oxygen tension for any given level of alveolar ventilation and inspired oxygen tension. Recognizing the frequency and the magnitude of this problem, British and American authors $4,5,11,13$ have suggested that a minimum of 30 per cent oxygen should be used in inspired air during anaesthesia. Bendixen and his co-workers ${ }^{0,10}$ have suggested that much of the physiological shunt is related to minor but diffuse atelectasis, and that this may be offset by intermittent maximum inflations of the lung, replacing the intermittent sighs occurring reflexly during consciousness.

In a study recently completed in Toronto ${ }^{14}$ involving measurement of alveolararterial oxygen difference over a two-hour period, enlarged physiological shunts were noted. The figures confirm the values found in other centres, but are of additional interest in that the inspired gas was 70 per cent nitrogen and 30 per cent oxygen, serving as a vehicle for 0.5 per cent halothane. Vigorous maximum lung inflations were carried out every thirty minutes. Despite these precautions, the alveolar-arterial gradient was not always normal, and we must agree with Nunn $^{5}$ that factors other than atelectasis are likely to be important. Figure 4 summarizes the values found and compares them with normal values in individuals breathing room air. In this group of normal patients undergoing surgery on the periphery, anaesthesia was maintained with the gas mixture just described. The subjects were curarized and ventilated to a tidal volume one and a half times the normal value predicted by the Radford nomogram. This provided a mean alveolar oxygen tension of $186 \mathrm{~mm}$. $\mathrm{Hg}$ and a mean arterial carbon dioxide tension of $31 \mathrm{~mm}$. $\mathrm{Hg}$. Under these circumstances (with very little scatter among the alveolar values), the arterial oxygen tensions varied considerably, confirming the situation described by Nunn. The mean alveolar-arterial gradient of $54 \mathrm{~mm}$. $\mathrm{Hg}$ was not grossly abnormal. However, two standard deviations of the mean would have included arterial tensions as low as $79 \mathrm{~mm}$. $\mathrm{Hg}$. Clearly, lower inspired oxygen levels would have been ill advised under such circumstances, and we have further evidence supporting the popular thesis that the minimum inspired oxygen tension during anaesthesia should be considerably higher than in room air. The evidence that the same is true during the management of respiratory failure by intermittent positive pressure ventilation is not as complete, although our own data would suggest that oxygen-enriched inspired air is also advisable under such circumstances.

This, then, is one side of the oxygen tightrope. Is there a second side? Most of us would react to the potential hazard of hypoxaemia by increasing the inspired oxygen tension and by employing moderate hyperventilation, where this was practicable. I propose to examine each of these precautions with a view to determining whether they, in turn, introduce potential hazard. 
NORMAL
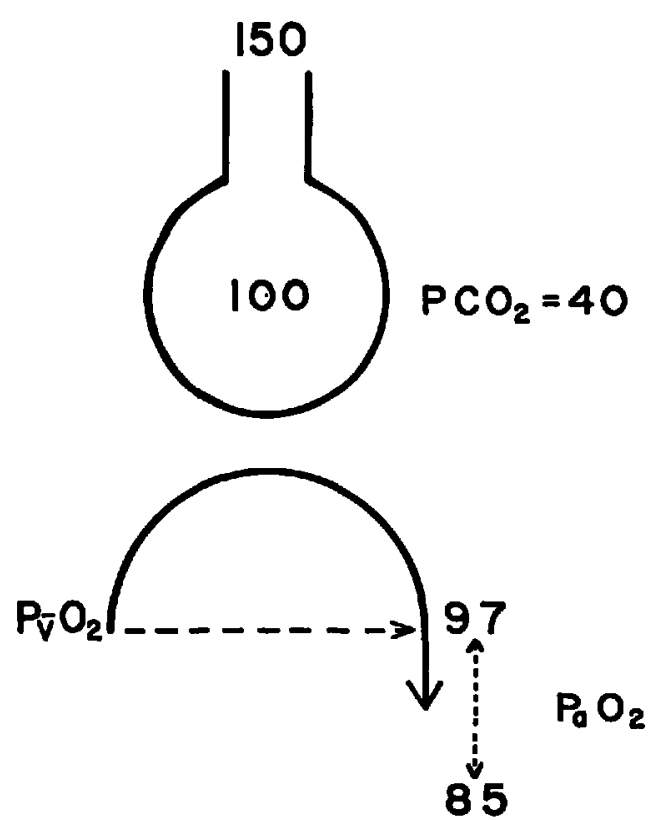

ANAESTHESIA

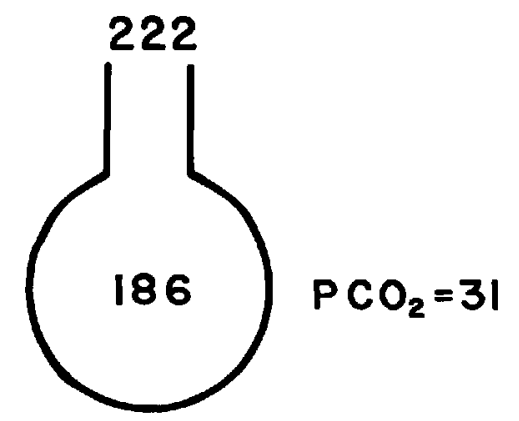

Ficure 4. Summary of values obtained during study controlling ventilation at 150 per cent of the Radford prediction. Figures represent oxygen tension in $\mathrm{mm}$. $\mathrm{Hg}$. Two standard deviations of the mean arterial oxygen tension are shown. The normal figures for spontaneous ventilation on room air are shown for comparison.

We have no data of our own of the possible harmful effects of oxygen-enriched inspired air. However, Déry has recently reported a fall in functional residual capacity and in arterial oxygen tension during anaesthesia in patients breathing 100 per cent oxygen. He was unable to detect the same change when the inspired gas contained 50 per cent nitrogen. ${ }^{15}$ It is entirely conceivable that much of the frequently occurring "miliary sub-radiological atelectasis" seen postoperatively ${ }^{10}$ may be avoided by renitrogenating patients at the end of the operation and, at the same time, maximally inflating their lungs.

Over longer periods, the possibility of pulmonary oxygen toxicity is receiving increasing attention, ${ }^{17,18}$ and concern has been expressed elsewhere ${ }^{19}$ over ventilators delivering high inspired oxygen concentrations. We have reason to believe that we may have produced pulmonary damage by this means on more than one occasion. ${ }^{20}$

There may, then, be an upper limit of safety for inspired oxygen levels. I know of no good data indicating absolute values for these levels in man. However, they may well lie in the region of 350 to $400 \mathrm{~mm}$. $\mathrm{Hg}$.

The permissible limits of inspired oxygen tension may be different in patients with pulmonary disease, since not only is there the hazard of depression of ventilation in those with chronic carbon dioxide retention who are breathing spontaneously, but the chronically under-ventilated alveolus may be more than normally susceptible to oxygen toxicity at lower levels of inspired oxygen. I know 
of no information on the latter point, and certainly, during spontaneous ventilation, this is unlikely to become a problem. However, when intermittent positive pressure is applied optimally there is evidence suggesting that the distribution of ventilation may be improved. ${ }^{21}$ If this were to occur, previously under-ventilating alveoli would be exposed to a much greater relative increase in oxygen tension than their more normally ventilating neighbours. Under such circumstances, increased susceptibility would be understandable.

It remains to examine the efficacy of hyperventilation in the prophylaxis of hypoxaemia. Our preliminary studies suggest not only that this may not always be helpful, but that on occasion it may produce increasing hypoxaemia.

In order to display arterial values obtained during hyperventilation we have used the $\mathrm{O}_{2}-\mathrm{CO}_{2}$ diagram. ${ }^{22}$ Figure 5 shows a single value for arterial blood in a normal person breathing room air. The diagonal $R$-line is drawn through all

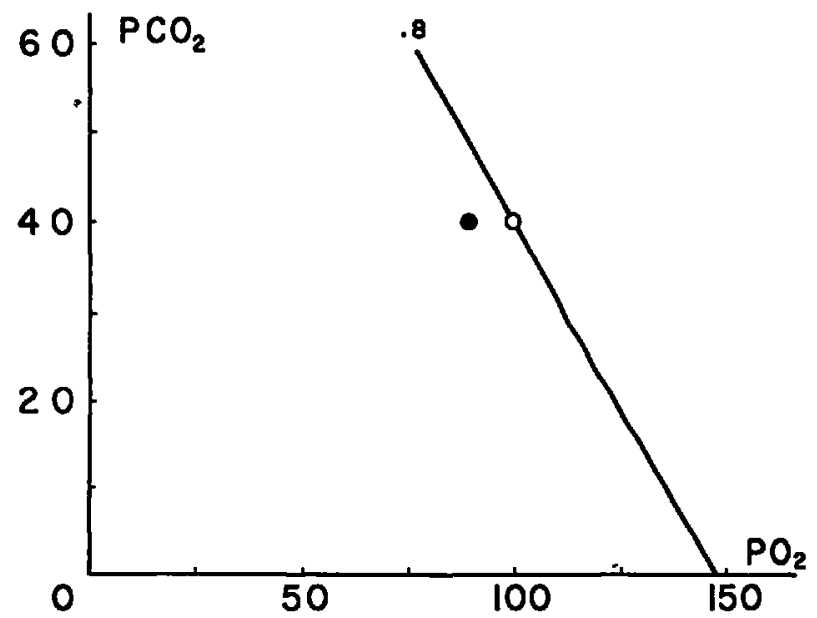

Ficure 5. Normal $\mathrm{O}_{2}-\mathrm{CO}_{2}$ diagram. Open dot represents alveolar point, and solid dot shows arterial value.

possible steady-state values for alveolar oxygen and carbon dioxide tension, for different levels of alveolar ventilation, assuming a respiratory quotient of 0.8 . This $R$-line passes through an inspired gas point with zero carbon-dioxide tension and an inspired oxygen tension of $148 \mathrm{~mm}$. Hg. The alveolar gas point is shown as an open circle and has a carbon dioxide tension of $40 \mathrm{~mm}$. $\mathrm{Hg}$ and an oxygen tension of $100 \mathrm{~mm}$. Hg. Comparing the arterial and alveolar points, there is no appreciable alveolar-arterial carbon-dioxide difference, but there is an oxygen gradient of $10 \mathrm{~mm}$. $\mathrm{Hg}$. The latter is measured as the horizontal difference from the $R$-line. Although Bendixen et al. have pointed out that large shunts may create an alveolar-arterial carbon dioxide difference, ${ }^{23}$ the error produced by calculations depending upon horizontal displacement from the arterial point when alveolar values are assumed from an $\mathrm{O}_{2}-\mathrm{CO}_{2}$ diagram would be small.

During hyperventilation the alveolar point will move towards the inspired point, always lying on the $R$-line when steady state is achieved. The arterial point should always move downwards and to the right and should remain the same distance from the $R$-line if the alveolar-arterial oxygen difference remains constant. Figures 6,7 , and 8 show arterial values obtained from conscious volunteers 

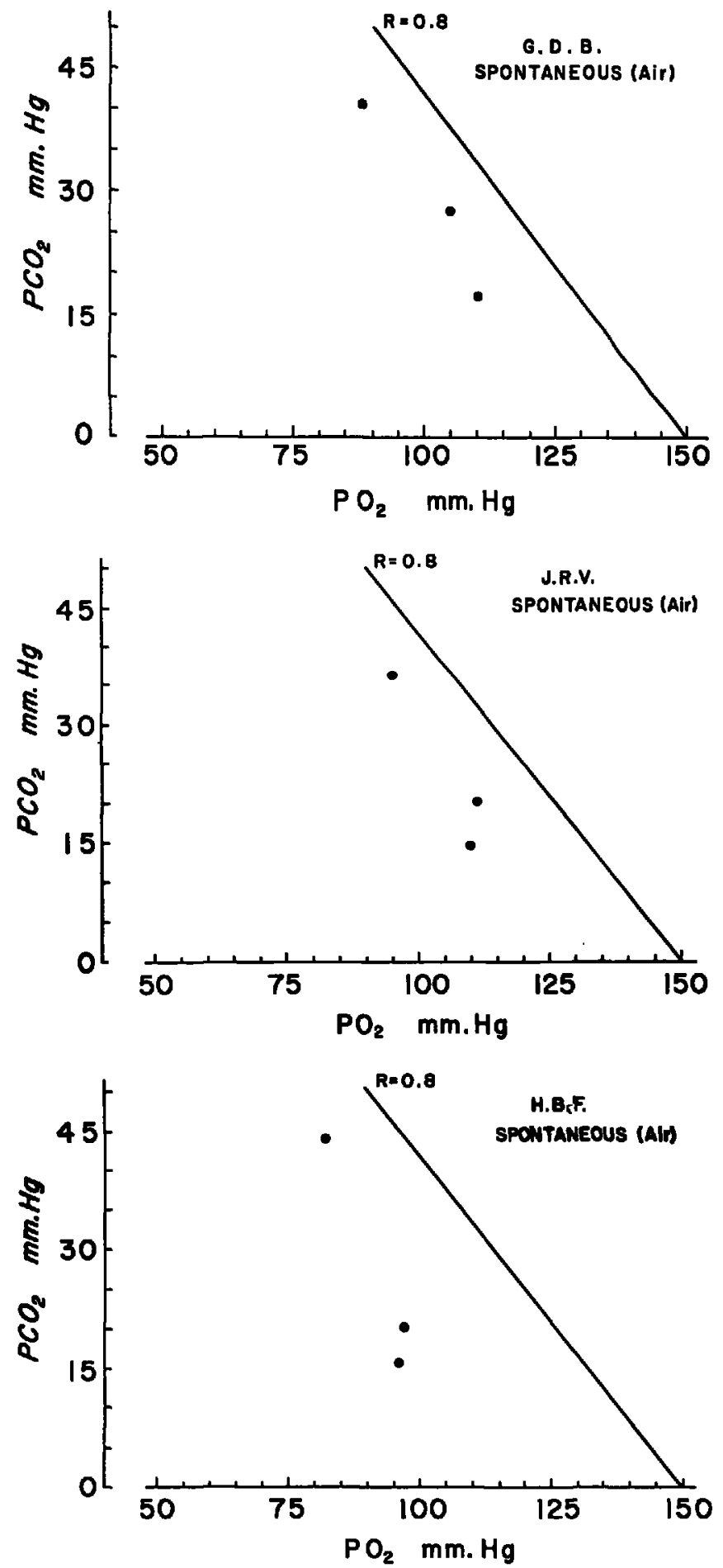

Ficures 6,7 , and $8 . \mathrm{O}_{2}-\mathrm{CO}_{2}$ diagrams showing arterial values obtained from supine normal subjects during three levels of steady-state ventilation. 
breathing room air, assuming $R Q$ equals 0.8 . Ventilation was maintained at a constant rate, in unison with a background cyclical noise. Expiration was carried out through a Wright respirometer, and the tidal volume was kept constant. An arterial sample was taken at the end of fifteen minutes and repeated after five more minutes. Steady state was assumed when reproducibility was achieved for arterial carbon-dioxide tension. The procedure was repeated at three different tidal volumes. In each subject, an increase in alveolar-arterial oxygen gradient occurred at the lowest carbon-dioxide tensions, and this may be related to the shift in the dissociation curve, as pointed out by Nunn. ${ }^{5}$

Using the format outlined above, the effects of hyperventilation by intermittent positive pressure were studied in a group of patients with respiratory failure (Figs. 9 to 14). The $R$-line is omitted from Figure 10, since the patient in question could not tolerate ventilation with room air and the inspired point is therefore off the diagram.

The clinical diagnosis and pulmonary status of the five patients are outlined in Table I.

TABLE I

\begin{tabular}{|c|c|c|}
\hline Fig. no. & Diagnosis & Pulmonary status \\
\hline 9 & Head injury: decerebrate & $\begin{array}{l}\text { Recent vigorous } \\
\text { P.N.P. ventilation for } \\
48 \text { hours. Some patchy } \\
\text { atelectasis vigorously } \\
\text { treated by physiotherapy } \\
\text { and maximum inflations. }\end{array}$ \\
\hline $\begin{array}{l}10 \\
11\end{array}$ & $\begin{array}{l}\text { Polyneuritis } \\
\text { Polyneuritis }\end{array}$ & $\begin{array}{l}\text { Mild bronchopneumonia. } \\
\text { Some muco-purulent } \\
\text { secretion. No clinical }\end{array}$ \\
\hline $\begin{array}{l}12 \\
13\end{array}$ & $\begin{array}{l}\text { Same patient as Fig. } 11 \\
\text { Traumatic quadriplegia }\end{array}$ & $\begin{array}{l}\text { or radiological pneumonia. } \\
24 \text { hours later. } \\
\text { Copious muco-purulent } \\
\text { secretions. No frank }\end{array}$ \\
\hline 14 & Traumatic quadriplegia & $\begin{array}{l}\text { No clinical pulmonary } \\
\text { abnormalities. }\end{array}$ \\
\hline
\end{tabular}

Since the presence of secretions was a problem in certain of these patients, tracheo-bronchial toilet was performed before each hyperventilation period. In two instances, this manoeuvre was performed following the collection of the arterial sample at the lowest carbon-dioxide tension, and the sampling was then repeated. This failed to show any significant change in oxygen tension.

This particular investigation was part of a pilot study comparing ventilators and, for this reason, the values obtained from hyperventilation by the Bird Mark 7, Engstrom, and Mörch ventilators appear in these figures. No conclusions can be drawn from the small differences found.

It is obvious that, in certain instances, hyperventilation by intermittent positive pressure may produce no gain in arterial oxygen tension and may even exaggerate hypoxaemia. The reasons for this are not apparent but four possibilities exist:

1. If intra-alveolar pressures are raised sufficiently high, pulmonary blood flow may be impeded with a resulting fall in diffusion. Marked hypotension did not occur in this study, and this possibility is considered most unlikely. 

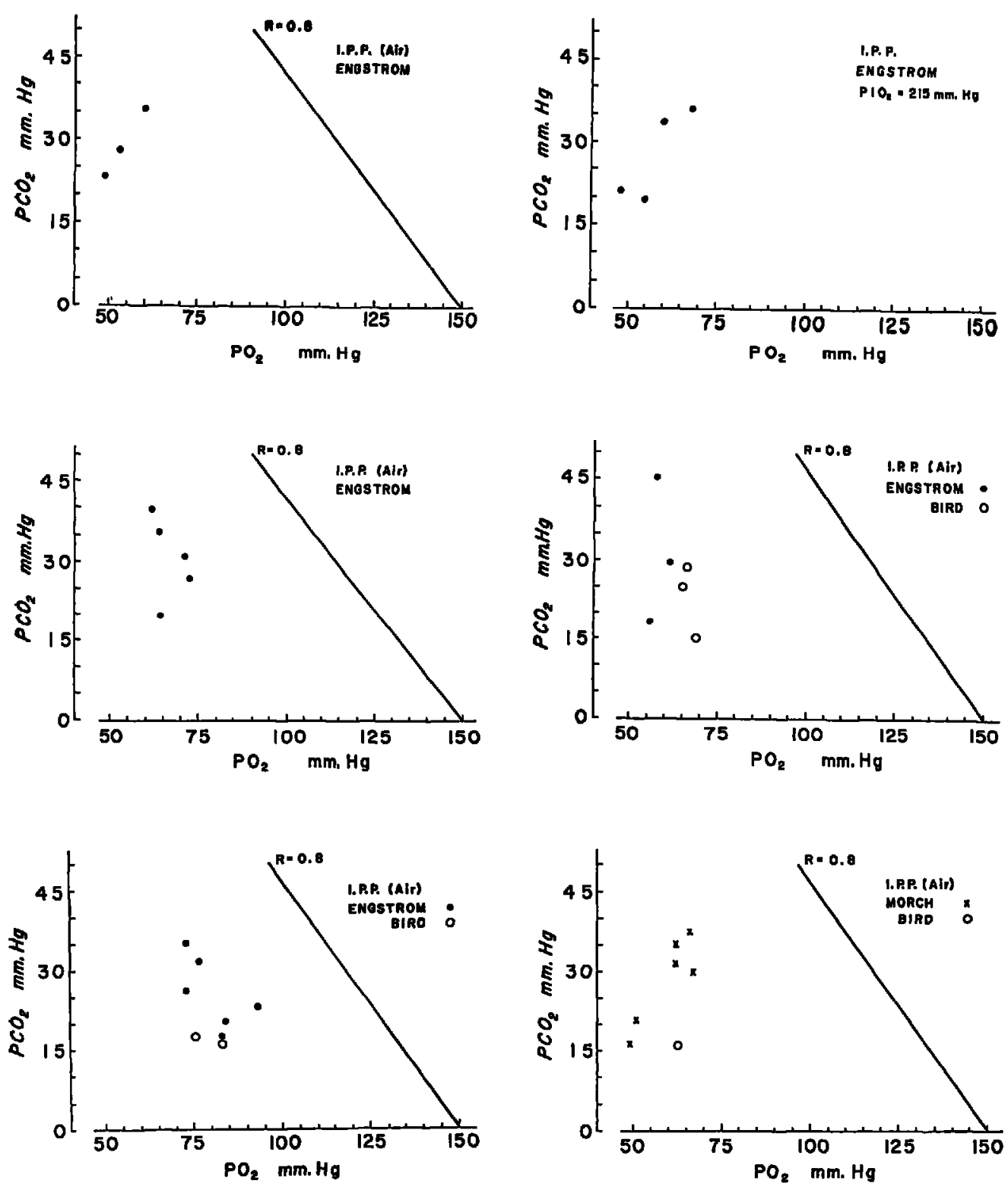

Figures $9,10,11,12,13,14$ (left to right). $\mathrm{O}_{2}-\mathrm{CO}_{2}$ diagrams showing arterial values obtained during different levels of steady-state ventilation, achieved by intermittent positive pressure ventilation in subjects with respiratory failure. (See Table I.)

2. An exaggeration of ventilation-perfusion abnormality cannot be excluded, using the available data, and remains a possible contributing factor.

3. The effects of the shift of the dissociation curve on arterial values ${ }^{6}$ and on the mixed venous oxygen tension ${ }^{22}$ will inevitably be contributing factors.

4. In patients with an elevated physiological shunt, as demonstrated by an exaggerated alveolar-arterial oxygen gradient at normal carbon-dioxide levels, the contribution of the mixed venous blood to the arterial levels will assume 
greater importance than usual. Not only will mixed venous oxygen tensions be lowered by hypocarbia but they may also be affected by any reduction in cardiac output produced by over-zealous intermittent positive pressure ventilation. Effects on cardiac output produced by I.P.P. will most likely occur during anaesthesia using agents which depress the cardiovascular system, in hypovolaemic patients and in those with disease entities known to embarrass cardiovascular and autonomic responses. The effect of any reduction in mixed venous oxygen tension will be most evident on the arterial side of the circulation when physiological shunt is large and when alveolar oxygen tensions are not artificially raised by oxygenenriched inspired air.

In this group of patients there were no means of detecting changes in cardiac output, and mixed venous blood was not sampled.

These considerations suggest that intermittent positive pressure hyperventilation, achieved by increasing tidal volume, may not improve the alveolar-arterial oxygen gradient as has been suggested ${ }^{13,24}$ but, under certain circumstances, may even detract from effective oxygenation. It should be added that the shift of the dissociation curve to the left will require a lower tissue oxygen tension for a given quantity of oxygen to be released-a further disadvantage not evident from a consideration of tension values alone.

In summary, then, during anaesthesia and during respiratory assistance with intermittent positive pressure ventilation, abnormally large alveolar-arterial oxygen gradients occur frequently and require the administration of oxygenenriched inspired air. I have suggested that we may be walking a therapeutic tightrope, since 100 per cent oxygen is disadvantageous. What are the limits? In normal individuals, 30 to 60 per cent inspired oxygen is probably reasonable, although it may be necessary to define the lower limits in terms of arterial carbondioxide tension. There is insufficient data presently available to clarify this point. It is also suggested that, when chronic pulmonary disease is handled by intermittent positive pressure ventilation, it may be necessary to lower the upper limit of permissible inspired oxygen percentage.

The term "tightrope" may be an exaggeration. However, the problems stated do exist and delineate a usually negotiable gangplank.

\section{SUMMARY}

During anaesthesia and during the management of respiratory failure by intermittent positive pressure ventilation, incipient hypoxaemia is common owing to the frequent occurrence of an increased physiological shunt. This hypoxaemia may be offset by raising the inspired oxygen tension and by hyperventilation. The former may produce alveolar collapse over short periods, and pulmonary oxygen toxicity if sustained. The latter can be shown to exaggerate hypoxaemia under certain circumstances.

The thesis is propounded that there is an upper and lower safe limit for the inspired oxygen tension, that these limits may be partially dependent upon carbon-dioxide levels, and that they may differ in patients with chronic pulmonary disease. 


\section{RÉsUMÉ}

On reconnait que l'hypoxémie est fréquente durant l'anesthésie accompagnée de ventilation spontanée ou contrôlée, de même qu'au cours du traitement prolongué de défaillances respiratoires par la technique de ventilation par pression positive intermittente.

On est généralement d'avis qu'on peut prévenir cette hypoxémie en augmentant la pression d'oxygène inspiré et en pratiquant l'hyperventilation. L'usage excessif de l'une ou l'autre de ces techniques est dangereux et on émet l'opinion qu'il vaut mieux administrer un taux précis d'oxygène qui peut varier avec le degré de ventilation et avec la présence d'une pathologie pulmonaire.

\section{ACKNOWLEDGMENTS}

The author wishes to thank Dr. J. F. Nunn and his co-authors for the opportunity to read their manuscript ${ }^{5}$ prior to its publication.

\section{REFERENCES}

1. Bendixen, H. H. \& Laven, M. B. Hypoxia in Anesthesia. A Review. Clin. Pharmacol. Therap. 6: 510 (1965).

2. Ramne, J. M. \& Bishop, J. M. A-a Difference in $\mathrm{O}_{2}$ Tension and Physiological Dead Space in Normal Man. J. Appl. Physiol. 18: 284 (1963).

3. Farm, L. E. \& Ramn, H. A Theoretical Analysis of the Alveolar-arterial Oxygen Difference with Special Reference to the Distribution Effect. J. Appl. Physiol. 7: 699 (1955).

4. Nunv, J. F. Factors Influencing the Arterial Oxygen Tension during Halothane Anaesthesia with Spontaneous Respiration. Brit. J. Anaesth. 36: 327 (1964).

5. Nunn, J. F.; Brraman, N. A.; \& Coleman, A. J. Factors Influencing the Arterial Oxygen Tension during Anaesthesia with Artificial Ventilation. Brit. J. Anaesth. In press.

6. Frumin, M. J.; Bergman, N. A.; Holaday, D. A.; Rackow, H.; \& Salanitre, E. Alveolar-arterial $\mathrm{O}_{2}$ Differences during Artificial Respiration in Man. J. Appl. Physiol. 14: 694 (1959).

7. Campreld, E. J. M.; Nunn, J. F.; \& Pecketr, B. W. A Comparison of Artificial Ventilation and Spontaneous Respiration with Particular Reference to Ventilation-bloodflow Relationships. Brit. J. Anaesth. 30: 166 (1958).

8. Stark, D. C. C. \& SMrth, H. Pulmonary Vascular Changes during Anaesthesia. Brit. J. Anaesth. 32: 460 (1960).

9. Bendixen, H. H.; Hedlex-Whyte, J.; \& LAver, M. B. Impaired Oxygenation in Surgical Patients during General Anesthesia with Controlled Ventilation. New England J. Med. 269: 823 (1963).

10. Bendixen, H. H.; Bullwinkel, B; Hedley-Whyte, J.; \& Laver, M. B. Atelectasis and Shunting during Spontaneous Ventilation in Anesthetized Patients. Anesthesiology. 25: 297 (1964).

11. Slater, E. M.; Nusson, S. E.; Leake, D. L.; Parry, W. L.; Laver, M. B.; HedleyWhyte, J.; \& Bendixen, H. H. Arterial Oxygen Tension Measurements during Nitrous-Oxide-Oxygen Anesthesia. Anesthesiology. 26: 642 (1965).

12. Theye, R. A. \& Tuory, G. F. Considerations in the Determination of Oxygen Uptake and Ventilatory Performance during Methoxyflurane Anesthesia in Man. Anesth. Analg. Curr. Res. 43: 306 ( 1964).

13. Sykes, M. K.; Younc, W. E.; \& Ronnsson, B. E. Oxygenation during Anaesthesia with Controlled Ventilation. Brit. J. Anaesth. 37: 314 (1965).

14. Fatrley, H. B. \& Blenkarn, G. D. Effect on Pulmonary Gas Exchange of Variations in Inspiratory Flow Rate during Intermittent Positive Pressure Ventilation. Brit. J. Anaesth. In press.

15. DÉray, R.; Pelletier, J.; Jacques, A.; Clavet, M.; \& Houde, J. Alveolar Collapse Induced by Denitrogenation. Canad. Anaesth. Soc. J. 12: 531 (1965).

16. Nunn, J. F. \& PAYNE, J. P. Hypoxaemia after General Anaesthesia. Lancet. ii: 631 (1962). 
17. Pratr, P. C. Pulmonary Capillary Proliferation Induced by Oxygen Inhalation. Amer. J. Pathol. 34: 1033 (1958).

18. - The Reaction of the Human Lung to Enriched Oxygen Atmosphere. Ann. New York Acad. Sc. 121: 809 (1965).

19. Fatruey, H. B. \& BrTrt, B. A. The Adequacy of the Air-Mix Control in Ventilators Operated from an Oxygen Source. Canad. M.A.J. 90: 1394 (1964).

20. Famplex, H. B. \& Chambers, R. A. The Management of the Patient with Respiratory Insufficiency. Canad. Anaesth. Soc. J. 7: 478 (1960).

21. Briscoe, W. A. \& Cournand, A. The Degree of Variation of Perfusion and of Ventilation within the Emphysematous Lung, and Some Related Considerations. Ciba Foundation Symposium: Pulmonary Structure and Function. London: Churchill (1962).

22. RAHN, H. \& FENN, W. O. The $\mathrm{O}_{2}-\mathrm{CO}_{2}$ Diagram: A Graphical Analysis of the Respiratory Gas Exchange. Washington, D.C.: Amer. Physiol. Soc. (1955).

23. Bendixen, H. H.; Egrert, L. D.; Hedley-Whyte, J.; Laver, M. B.; \& Pontoppman, H. Respiratory Care. St. Louis: Mosby (1965).

24. HeDley-Whyte, J; Laver, M. B.; \& Bendixen, H. H. Effect of Changes in Tidal Ventilation on Physiologic Shunting. Amer. J. Physiol. 206: 891 (1964). 